\title{
MOLECULAR-BIOLOGICAL ANALYSIS OF VANCOMYCIN-RESISTANT ENTEROCOCCI ISOLATED FROM A COMMUNITY IN THE CZECH REPUBLIC
}

\author{
Milan Kolář, Luboslava Čekanová, Iva Vágnerová, Michaela Kesselová, Pavel Sauer, \\ Dagmar Koukalová, Petr Hejnar
}

Institute of Microbiology, Faculty of Medicine, Palacký University, Olomouc, Czech Republic

e-mail: kolar@fnol.cz

Received: September 15, 2004; Accepted: October 20, 2004

Keywords: Enterococci/Resistance/Glycopeptides

Objective: To determine the occurrence of vancomycin-resistant enterococci (VRE) in a community of the Czech Republic and a molecular-biological analysis of the VRE isolated.

Methods: Enterococci were isolated from the rectal swabs of healthy people in the Olomouc region (population 300,000), Czech Republic in the period of January - December 2003. The molecular-biological analysis of VRE was performed by analysis of isolated DNA, which was cleaved by restriction enzyme SmaI and separated by pulse field gel electrophoresis (PFGE).

Results: A total number of 5,283 swabs were evaluated and 558 Enterococcus sp. strains were isolated during the follow-up period. 9 strains (1.6\%) were identified as VRE. Two strains were E. faecium phenotype VanA, one strain was E. faecalis phenotype VanB, two strains were E. gallinarum phenotype VanC and four strains were $E$. casseliflavus phenotype VanC. PFGE was used to obtain 9 different restriction profiles of VRE strains. The analysis showed closer a similarity of $E$. casseliflavus strains (80-95\%) than between E. faecium strains ( $41 \%$ ).

Conclusions: The presence of VRE in a sample community of the Czech population was confirmed. It is clear that it is necessary to take into account the possibility of VRE spreading from the community into health care facilities.

\section{INTRODUCTION}

At present, bacterial resistance to antibiotics is a very important medical problem. More and more new bacterial strains emerge with a dangerous degree of resistance, among others vancomycin-resistant enterococci (VRE). For the treatment of enterococcal infections in humans, ampicillin and aminoglycosides can be used as the drugs of choice. Diseases caused by strains which are resistant to ampicillin and aminoglycosides can be treated with vancomycin or teicoplanin. For this reason, VRE occurrence represents a serious problem. VRE were first described in 1987 in Europe and their incidence been increasing since 1988 world wide ${ }^{1,2}$. The occurrence of VRE in the health care facilities in the Czech Republic has been already described ${ }^{3,4}$.

The aim of this study was the monitoring of VRE in the community of one region of the Czech Republic and molecular-biological analysis of the VRE isolated.

\section{MATERIALS AND METHODS}

Targeted screening of VRE occurrence in a sample of the community of the Olomouc region (population 300,000) Czech Republic, was performed in the period of January - December 2003. Rectal swabs of non-hospitalized persons were examined. Each specimen was cultivated on blood agar (Becton Dickinson) with following identification of present enterococci according to the criteria of Facklam and Collins, an evaluation of the biochemical properties was done with the help of the Encoccus test (Lachema, Czech Republic) ${ }^{5}$. All VRE were analysed for the group D antigen presence (Oxoid). Resistance to vancomycin and teicoplanin was determined by a standard dilution micromethod in accordance with the NCCLS guideline ${ }^{6}$. The values of $4 \mathrm{mg} / \mathrm{L}$ for vancomycin and $8 \mathrm{mg} / \mathrm{L}$ for teicoplanin were used as breakpoints. To determine the phenotypes of glycopeptide resistance, vancomycin and teicoplanin were diluted to concentrations $2-1024 \mathrm{mg} / 1$. The dilution quality of both antibiotic agents was checked with the help of reference strains Staphylococcus aureus ATCC 29213 and Enterococcus faecalis ATCC 29212. Species identification and glycopeptide resistance genotypes of vancomycin-resistant strains were confirmed by multiplex PCR as described previously?.

Molecular analysis of vancomycin-resistant enterococci

$20 \mathrm{ml}$ of Mueller-Hinton broth was inoculated by bacterial culture of Enterococcus sp. strain and incubated overnight at $37^{\circ} \mathrm{C}$. The culture was cooled down to $4^{\circ} \mathrm{C}$ and spun at $4000 \mathrm{rpm}$ for $15 \mathrm{~min}$. Supernatant was poured off and the pellet was redissolved in $10 \mathrm{ml}$ of cool washing buffer ( $10 \mathrm{mM}$ Tris/HCl, $10 \mathrm{mM}$ EDTA, $10 \mathrm{mM}$ EGTA, $1 \mathrm{M} \mathrm{NaCl}, \mathrm{pH} 7.5$ ). This washing procedure was 
repeated twice and then the bacterial culture was resuspended in the same solution to $\mathrm{OD}_{600}=0.3 .10 \mathrm{ml}$ of bacterial solution was centrifuged at $4000 \mathrm{rpm}$ for $15 \mathrm{~min}$ and resuspended in $100 \mu \mathrm{L}$ of the same solution, warmed up to $55^{\circ} \mathrm{C}$ for $3 \mathrm{~min}$ and mixed with $100 \mu \mathrm{l} 2 \%$ low melting point agarose in $50 \mathrm{mM}$ Tris/ $\mathrm{HCl}, 5 \mathrm{mM}$ EDTA, $\mathrm{pH} 8$. The suspension was transferred into the wells of a block maker and placed in the fridge for $20 \mathrm{~min}$. Tough blocks were transferred into $1 \mathrm{ml}$ of lysis solution $(6 \mathrm{mM}$ Tris/ $\mathrm{HCl}, 100 \mathrm{mM}$ EDTA, $1 \mathrm{M} \mathrm{NaCl}, 0.5 \%$ Brij 58, 0.2 \% NaDeoxycholate, $0.5 \%$ laurylsarcosine, $500 \mu \mathrm{g}$ lysosyme), incubated overnight at $37^{\circ} \mathrm{C}$ and then placed into $1 \mathrm{ml}$ of deprotein solution (25 mM EDTA, 20 mM EGTA, $1 \%$ laurylsarcosine and $500 \mu \mathrm{g}$ Proteinase-K) and incubated $12 \mathrm{~h}$ at $55^{\circ} \mathrm{C}$. After this procedure the blocks were washed 5 times with $10 \mathrm{ml}$ of TE buffer.

Restriction cleavage of the blocks $1 \times 1 \times 5 \mathrm{~mm}$ was performed in restriction solution $(8 \mu \mathrm{L}$ restriction buffer for SmaI, $65 \mu \mathrm{L}$ deionised water and $1 \mu \mathrm{L}$ of restriction enzyme $S m a I)$. The blocks were incubated at $25^{\circ} \mathrm{C}$ overnight.

PFGE was prepared in $1.2 \%$ agarose gel in $1 \mathrm{xTBE}$ buffer. The blocks with cleaved DNA were placed into the wells of the gel and covered with $0.8 \%$ low melting point agarose. PFGE had been running for $28 \mathrm{~h}$ at pulse time from 1 to $90 \mathrm{~s}, 5.0 \mathrm{~V} / \mathrm{cm}$. The gel was stained in etidium bromide solution $(1 \mu \mathrm{g} / \mathrm{ml})$ and analysed by the GelCompare programme.

\section{RESULTS}

During the follow-up period, 5,283 rectal swabs were collected and a total number of 558 enterococci isolated. 485 enterococci ( $87 \%$ ) were identified as Enterococcus faecalis strains, 39 enterococci (7\%) as Enterococcus faecium and 34 enterococci (6\%) were classified as others (Enterococcus sp.).

Resistance of E. faecalis (485 strains) and E. faecium (39 strains) to antimicrobial agents is given in Table 1.

Table 1. Resistance of E. faecalis and E. faecium strains to antibiotics

\begin{tabular}{|l|c|c|}
\hline \multirow{2}{*}{ Antibiotic } & \multicolumn{2}{c|}{ Resistance (\%) } \\
\cline { 2 - 3 } & $\begin{array}{c}\text { E. faeca- } \\
\text { lis }\end{array}$ & $\begin{array}{c}\text { E. fae- } \\
\text { cium }\end{array}$ \\
\hline ampicillin & 2 & 77 \\
erythromycin & 42 & 77 \\
gentamicin (high-level resistance) & 1 & 18 \\
streptomycin (high-level resistance) & 2 & 23 \\
teicoplanin & 0 & 5 \\
tetracycline & 67 & 46 \\
vancomycin & 0.2 & 5 \\
\hline
\end{tabular}

Resistance to vancomycin was evidenced in 9 strains (1.6\%) isolated from 9 different persons who were not hospitalized, throughout the follow-up period. Two strains were detected as E. faecium phenotype VanA, one strain was $E$. faecalis phenotype VanB, two strains were $E$. gallinarum phenotype VanC and four strains were $E$. casseliflavus phenotype VanC. A survey of VRE from the community with minimal inhibition concentrations of vancomycin and teicoplanin is given in Table 2.

Table 2. Survey of isolated species of VRE and their phenotypes

\begin{tabular}{|c|c|c|c|c|}
\hline \multirow{2}{*}{ 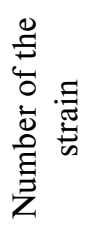 } & \multirow[b]{2}{*}{ Species } & \multirow{2}{*}{ 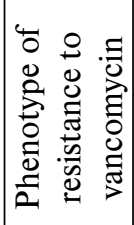 } & \multicolumn{2}{|c|}{$\begin{array}{l}\text { Minimal inhibition } \\
\text { concentration }(\mathrm{mg} / \mathrm{L})\end{array}$} \\
\hline & & & vancomycin & $\begin{array}{l}\text { teico- } \\
\text { planin }\end{array}$ \\
\hline 1 & $\begin{array}{l}\text { Enterococcus } \\
\text { faecium }\end{array}$ & VanA & 512 & 512 \\
\hline 2 & $\begin{array}{l}\text { Enterococcus } \\
\text { faecium }\end{array}$ & VanA & 512 & 64 \\
\hline 3 & $\begin{array}{l}\text { Enterococcus } \\
\text { faecalis }\end{array}$ & VanB & 8 & 0.5 \\
\hline 4 & $\begin{array}{l}\text { Enterococcus } \\
\text { casseliflavus }\end{array}$ & VanC & 16 & 0.25 \\
\hline 5 & $\begin{array}{l}\text { Enterococcus } \\
\text { casseliflavus }\end{array}$ & VanC & 16 & 0.5 \\
\hline 6 & \begin{tabular}{|l} 
Enterococcus \\
gallinarum
\end{tabular} & VanC & 8 & 0.5 \\
\hline 7 & $\begin{array}{l}\text { Enterococcus } \\
\text { casseliflavus }\end{array}$ & VanC & 8 & 1 \\
\hline 8 & \begin{tabular}{|l} 
Enterococcus \\
gallinarum
\end{tabular} & VanC & 8 & 0.25 \\
\hline 9 & \begin{tabular}{|l} 
Enterococcus \\
casseliflavus
\end{tabular} & VanC & 8 & 0.5 \\
\hline
\end{tabular}

9 different restriction profiles of VRE strains were obtained by analysis of isolated DNA (Fig. 1). Analysis using the GelCompare programme showed closer similarity of $E$. casseliflavus strains (95\% between strains 4-5 and $80 \%$ of these two with strain 7 ) than similarity between E. faecium strains ( $41 \%)$.

\section{DISCUSSION}

Increase in bacterial resistance to antibiotics and the rising frequency of bacterial strains with a dangerous level of resistance is a serious problem these days. The application of antibiotics brings an increase of resistance to antibiotics not only in pathogenic bacterial strains, but also in strains forming a part of the endogenous flora of humans. The study presented is a description of VRE of community origin in one region of the Czech Republic, complementing studies dealing with the incidence of VRE strains in health care facilities in the same region of Czech Republic ${ }^{3,8}$. 


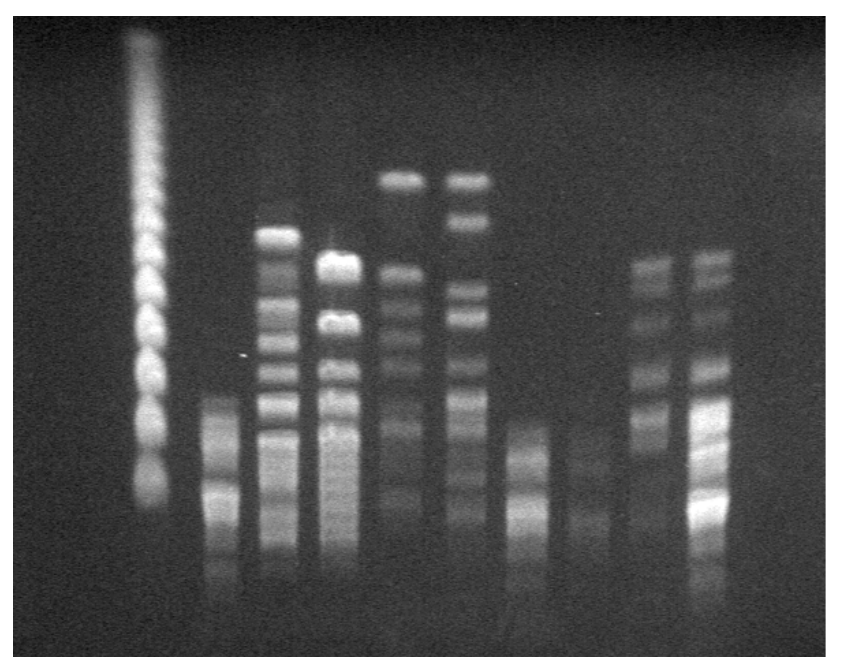

Lane $\quad \begin{array}{llllllllll}1 & 2 & 3 & 4 & 5 & 6 & 7 & 8 & 9 & 10\end{array}$

Lane 1 - marker

Lane 6 - VRE No. 6

Lane 2 - VRE No. 4

Lane 3 - VRE No. 3

Lane 4 - VRE No. 2

Lane 5 - VRE No. 1

Lane 7 - VRE No. 5

Lane 8 - VRE No. 7

Lane 9 - VRE No. 9

Lane 10 - VRE No. 8

Fig. 1. Restriction profiles of VRE strains

In Europe the rate of fecal carriage of VRE in the community varies from 2 to $28 \%$ and vancomycin resistance is mostly VanA mediated ${ }^{9,}$. The highest frequency of vancomycin-resistant strains in our study was confirmed for the E. casseliflavus species. In E. casseliflavus and $E$. gallinarum strains with VanC phenotype, the genetic determinants of resistance to vancomycin are inborn and non-transferable ${ }^{11,12}$. By contrast, in the E. faecium VanA and E. faecalis VanB strains, the resistance is acquired, transferable and much more serious from the epidemiological point of view. The frequency of vancomycin-resistant strains in E. faecalis reached $0.2 \%$ and $5 \%$ in $E$. faecium. On the whole, the rate of fecal carriage of VRE in the community of the region under consideration was shown in $1.6 \%$.

VRE have not yet prove to be important nosocomial pathogens in Europe. The reported percentage of VRE among nosocomial enterococcal infections have always been lower than $3 \%$, but these strains represent a potential danger mainly in immunocompromised patients ${ }^{13}$. At the University Hospital in Olomouc, VRE were isolated only at the Department of Hemato-oncology, where the most frequently identified VRE were E. faecium VanA (77\%) and E. faecalis VanB (12\%). It should be emphasised that most of these strains were isolated from stools $(57 \%){ }^{8}$ Basing on that information, it can be assumed that most of the VRE strains represent a colonisation of the gastrointestinal system without causing infection. Therefore an important current question is the source of VRE in hospitalized patients. There are two variants:

- The patient is infected via a suitable vehiculum in the hospital environment where VRE survive. The spreading is facilitated by various vectors, the most important of which is the hospital staff (namely their hands).
- The source of VRE is the microflora in the gastrointestinal tract of the hospitalized patient. This implies acceptance of the fact that there are people in the Czech community with VRE as a part of the normal intestinal microflora.

In the region of Olomouc, VRE were isolated from the clinical material of patients of the University Hospital in Olomouc and also from the healthy people in the community. It is therefore evident that it is necessary to take into account the possibility of the spreading of these strains from the community into health care facilities. A further opportunity of their spreading occurs in hospital divisions via environmental vectors and due to wide-specter antibiotic treatment.

\section{ACKNOWLEDGEMENTS}

The study was supported by the grant of IGA of the Ministry of Health, Czech Republic, No. NI/7305-3.

\section{REFERENCES}

1. Leclercq R, Derlot E, Duval J, Courvalin P. (1988) Plasmid-mediated resistance to vancomycin and teicoplanin in Enterococcus faecium. New Engl J Med 319, 157-61.

2. Uttley AHC, Collins CH, Naidoo J, George RC. (1988) Vancomycin-resistant enterococci. Lancet $1,57-8$.

3. Koláŕ M, Vágnerová I, Kohnová I. (1997) Detection of vancomycinresistant enterococci in Teaching Hospital, Olomouc. Klin Mikrobiol Inf Lék 3, 189-91.

4. Bergerová T, Turková S. (1997) First finding of vancomycin-resistant enterococci in the Faculty Hospital, Plzen. Klin Mikrobiol Inf Lék 3, 287-8.

5. Facklam RR, Collins MD. (1989) Identification of Enterococcus species isolated from human infections by conventional test scheme. J Clin Microbiol 27, 731-4.

6. National Committee for Clinical Laboratory Standards. (1995) Performance standards for antimicrobial susceptibility testing. Sixth informational supplement. Nat Comm Clin Lab Standards, Villanova, PA.

7. Dutka-Malen S, Evers S, Courvalin P. (1995) Detection of glycopeptide resistance genotypes and identification to the species level of clinically relevant enterococci by PCR. J Clin Microbiol 33, 24-7.

8. Koláŕ M, Vágnerová I, Látal T, et al. (2002) The occurrence of vancomycin-resistant enterococci in hematological patients in relation to antibiotic use. Microbiologica 25, 205-12.

9. Endtz HP, Van den Braak N, Van Belkum A, et al. (1997) Fecal carriage of vancomycin-resistant enterococci in hospitalized patients and those living in the community in the Netherlands. J Clin Microbiol 35, 3026-31.

10. Bruinsma N, Willems RJL, Van den Bogaard AE, et al. (2002) Different levels of genetic homogenity in vancomycin-resistant and -susceptible Enterococcus faecium isolates from different human and animal sources analyzed by amplified-fragment length polymorphism. Antimicrob Agents Chemother 46, 2779-83.

11. Murray BE. (1997) Vancomycin-resistant enterococci. Am J Med 101, 284-93.

12. Arthur M, Reynolds PE, Depardieu F, et al. (1996) Mechanisms of glycopeptide resistance in enterococci. J Infect 32, 11-6.

13. Schouten M, Hoogkamp-Korstanje J, Meis J, Voss A. (2000) Prevalence of vancomycin-resistant enterococci in Europe. Eur J Clin Microbiol 19, 816-22. 